\title{
Customer Aggression and Knowledge Hiding Among Service Employees: The Mediating Role of Emotional Exhaustion
}

\author{
Fengzhiwen $\mathrm{Cao}^{1, *}$ \\ ${ }^{I}$ The University of Sheffield, Western Bank, Sheffield S10 2TN, UK \\ *Corresponding author. Email: 812347054@qq.com
}

\begin{abstract}
The purpose of this research was to explore how customer aggression affects employees' emotional exhaustion and knowledge hiding, and whether employees' emotional regulation capability can moderate the relationship between customer aggression and emotional exhaustion. A questionnaire survey finally produced 201 valid cases. The results show that customer aggression significantly impacts employees' knowledge hiding through emotional exhaustion, and employees' emotional regulation capability amplify the positive relationship between customer aggression and emotional exhaustion. This paper extends the current research in terms of customer incivility and knowledge hiding.
\end{abstract}

Keywords: customer aggression, knowledge hiding, emotional exhaustion, emotional regulation capability

\section{INTRODUCTION}

In the context of current knowledge economy, having an effective knowledge management and knowledge learning system is one of the important measures to improve an organization's competitive advantage. However, the altitude and behavior of employees directly impact knowledge management system. And employees' attitudes and behaviors towards knowledge have the most direct impact on knowledge management system [1]. Among them, the knowledge sharing behavior of employees will greatly increase the utilization rate of knowledge and can significantly improve organizational benefits. However, knowledge sharing in organizations is generally expected rather than mandatory behavior. Not all employees will share knowledge, because employees believe that the organization does not own their "intellectual property rights" and cannot force their knowledge to be passed on to other members [2]. If the knowledge sharing behavior in the organization is restricted by the behavior of the employees, then a "knowledge gap" will be formed [3], and the existence of the "knowledge gap" may directly lead to organizational work lower than organizational expectations. Research shows that up to $78 \%$ of employees tend to conceal or refuse to provide their knowledge from colleagues, and they are more willing to keep them as exclusive tools and use them for personal gain. Only talents and organizations with professional knowledge can maintain continuous innovation in the competition, and effective knowledge management depends on each individual organization to be able to carry out sufficient knowledge sharing. However, employees generally prefer to maintain their irreplaceability within the organization through knowledge hiding. This is called "knowledge hiding" by researchers. Knowledge hiding is a common individual behavior in organizations, which seriously affects the survival and development of individual employees and organizations. It will not only increase the time cost of employees seeking knowledge, but also affect the output of the organization and reduce the organization's competitiveness and innovation capabilities.

Although many scholars have conducted rich research on how to reduce knowledge hiding behavior and promote knowledge sharing behavior, knowledge sharing in management practice is not as smooth as expected. Many companies have tried various measures to promote knowledge sharing, such as building a knowledge management platform, increasing material rewards, and creating a shared corporate culture atmosphere, but they have not achieved the expected results.

Throughout the current research on the antecedent variables of knowledge hiding, different scholars have also conducted research from different perspectives: knowledge ownership, leadership style (such as abuse 
management), interpersonal trust, knowledge sharing. In addition, according to the theory of resource preservation, employees tend to save and obtain resources that are valuable to them at work. Knowledge hiding is a manifestation of employees' protection of their intellectual property rights; according to the emotional exhaustion literature, employees are Need to consume their own emotional resources to complete better services, and the emotional management ability of employees will also affect the degree and speed of emotional exhaustion. In addition, customer aggression can cause emotional exhaustion and directly affect employee performance. To sum up, customer aggression is a negative interpersonal experience that consumes individual resources, and knowledge hiding is an active resource protection behavior, so customer aggression will affect the occurrence of knowledge hiding behavior. This research will be based on the path of "customer aggression-self-exhaustion-knowledge hiding", by introducing the mediating variable emotional exhaustion and the regulatory variable emotional management ability to explore the mechanism between customer aggression and knowledge hiding from the perspective of resources. Provide new hidden antecedent variables of knowledge.

\section{THEORY AND HYPOTHESIS}

\subsection{Customer aggression and employee emotional exhaustion}

Customer aggression refers to low-quality interpersonal treatment and conflict in the service delivery process of customers and employees, such as verbal abuse, disrespect, unfair demands, and so on. The customer service staff have been bullied by customers, and most of the customer service staff obviously feel the negative impact of customer aggression on their work. After employees are bullied by customers, employees need to invest more resources to deal with customer aggression, thereby reducing the pursuit of happiness. [4]. Research has found that customer verbal attacks are positively correlated with employees' turnover intentions, and negatively correlated with life satisfaction [5]. With the development of the service industry, competition among enterprises has focused more on the service attitudes of frontline service personnel to customers. Based on this concept, enterprises have put forward strict requirements on the attitude of service personnel. "Customer is God" is regarded as the golden rule by many companies. When an employee conflicts with a customer, unconditionally protecting the interests of customers becomes an inevitable choice for many companies. In this case, even if it is not the fault of the employee, the company often requires the employee to accept the result unconditionally. Front-line employees in the service industry are often bullied by customers. But they dare not say it. The final result is that when employees are bullied by customers, they often show negative emotions and increase their willingness to resign. A series of negative behaviors will have a serious negative impact on the performance and image of the company.

Customer aggression has a large negative impact on employees' psychology and emotions. When employees are bullied by customers, they need to adjust themselves, which will consume their own psychological energy. And an individual's mental energy is limited, so every selfregulation is a loss. Once this situation does not improve in the short term, individuals may lead to higher levels of self-depletion and emotional exhaustion. Existing studies have found that customer aggression behavior can lead to a decrease in individual job satisfaction. Grandey [6] found that customer aggression promotes employee selfloss.

Hypothesis 1: Customer aggression is positively correlated with employee emotional exhaustion.

\subsection{Emotional exhaustion and employee knowledge hiding behavior}

In the service industry, companies will require employees to provide customers with high-quality services with a sincere attitude, which requires employees to consume their own resource, such as energy, emotions, and labor. The so-called emotional exhaustion means that although the individual has done nothing, every choice, entanglement, anxiety, and distraction is a loss of his own mental energy; every time a bit of mental energy is consumed, executive ability and willpower will decrease. Psychological energy is indispensable to self-executive functions (self-control, choice) and psychological energy is limited, and only a limited number of self-control can be performed in a short period of time. All the executive functions of a person need the same kind of resources, and the loss of resources in one area will reduce the available resources in another area. The success of employees' selfcontrol depends on the amount of mental energy, and the process of self-control is the process of consuming mental energy. After consumption, it takes a while to recover, similar to the need to rest after muscle fatigue [7].

Once emotional exhaustion occurs, it will often lead to impaired self-esteem, tension and grumpiness, depression and anxiety of employees, thereby reducing employees' enthusiasm for work, increasing their antiproductive behavior and self-protection tendency, and ultimately affecting their attitudes towards work And behavior, the external manifestation is reluctance to communicate with others, such as knowledge sharing behavior and the decline of work performance, thereby reducing the efficiency of the organization and bringing losses to the organization.

Connelly et al. [8] proposed the concept of knowledge hiding for the first time and defined it as an individual's 
intentional behavior of retaining, hiding or refusing to give knowledge requested by others. Scholars who study this phenomenon tell us that people are extremely good at deliberately hiding knowledge while making others feel that they are not doing so. In the workplace, knowledge hiding is specifically manifested as an employee's deliberate reservation, concealment, and refusal to provide knowledge from another employee. The subject of the knowledge request is the individual employee, not the organization or a group in the organization. Therefore, knowledge hiding generally exists in modern organizations, and it has many negative effects on organizations and employees and needs to attract the attention of theoretical and practical circles. In the workplace, people who try to hide knowledge may often adopt the following methods: They may agree to share knowledge with you at the time, but have never acted afterwards. They may avoid confirming the specific discussion time with you, or postpone it under the pretext of busy work, hoping that you will forget it one day or give up. They may pretend that they don't know what you want while they actually do. Or, they may pretend to have some reasons why they cannot share, such as claiming that there are regulations prohibiting sharing, but in fact there is no such rule.

Employees have self-depletion due to customer aggression, and self-depletion will reduce employees' enthusiasm for work and bring negative emotions. Negative emotions at work may cause employees to refuse to communicate with others or to share things with other employees, such as help. Knowledge, etc., thereby affecting knowledge hiding behavior. The more selfdepletion and the higher the negative emotions, the more serious the phenomenon of knowledge hiding will be. The theory of resource conservation points out that people tend to acquire and save resources that are valuable to them. Employees will consume their own emotional resources and provide high-quality services in accordance with the requirements of the organization during the service process; but the consumption of these resources needs to be timely Supplement, the occurrence of customer aggression not only cannot make up for the consumption of employees' original emotional resources, but also requires employees to consume more emotional resources to deal with or face customer aggression, which in turn leads to exhaustion of emotional resources, which in turn leads to negative employees Attitudes and behaviors ultimately affect employees' knowledge hiding behaviors.

Hypothesis 2: Emotional exhaustion mediates the relationship between customer aggression behavior and employee knowledge hiding.

\subsection{The moderating effect of employees' emotional management ability}

Emotion management means to fully explore and cultivate the emotional intelligence of individuals and groups through learning the understanding, coordination, guidance, interaction and control of the emotions of oneself and others, and to develop the ability to control emotions, thereby ensuring that individuals and groups maintain good Emotional state, which produces good management results.

Customer aggression will bring negative emotions to employees. In order to continue working, employees have to self-regulate to adjust negative emotions, and selfregulation will bring self-loss, that is, customer aggression will accelerate employees' emotional exhaustion. However, different employees have different emotional management capabilities. Some employees may quickly adjust their emotions in the face of customer aggression and will not affect their work for a long time; while some employees have weak psychological qualities, and after being bullied by customers, the greater the emotional fluctuations, the more self-depletion, so the emotional management ability plays an important role, as a moderator, affects the emotional exhaustion of the employees caused by the customer aggression behavior.

Hypothesis 3: Employees' emotional management ability positively regulates the relationship between customer aggression and emotional exhaustion.

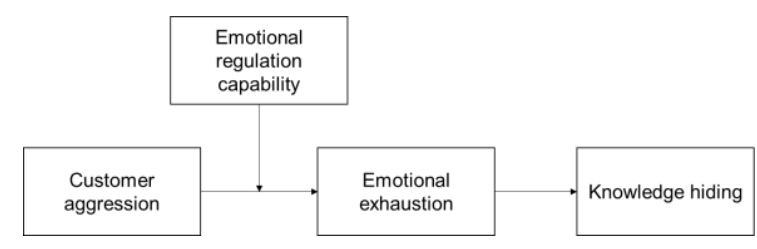

Figure 1 The research model

\section{METHODS}

\subsection{Sample and Procedures}

Data collection was carried out through enterprise of service industry within one week. The questionnaire is divided into five parts, including personal information, customer aggression, emotional exhaustion, knowledge hiding, and emotional regulation capability. In the description of the questionnaire, we have informed the respondents that the data will be used for scientific research only and their personal information will be kept confidential. Finally, we got 216 responses. Then, after removing the invalid questionnaire, we obtained a total of 201 cases for testing and analysis of hypotheses for subsequent research.

Among the 201 cases, 87 are male, accounting for $43.3 \%$; the average age of employees was 31.2 years; the average tenure of employees was 8.15 years; in terms of 
education, 6 people are with a high school education or less degree (3.0\%), 22 are with a college degree (10.9\%), 155 are with a bachelor degree $(77.1 \%)$, and 18 are with a master or higher degree $(9.0 \%)$.

\subsection{Measures}

All variables in this study used Likert's five-point scale to measure respondents' consent to the project, where 1 means "strongly disagree" and 5 means "strongly agree".

Customer aggression: The measurement of customer aggression adapts the scale of Shao and Skarlicki [9], which contains 5 questions in total. Representative measurement items are "Said inappropriate things." and "Used inappropriate gesture/body language ". In this study, Cronbach's coefficient on this scale was 0.85 .

Emotional exhaustion: As for the measures of emotional exhaustion, we used 3 items developed by Watkins et al. [10]. Sample items are "I feel emotionally drained from my work", and "I feel exhausted when I think about having to face another day on the job". In this study, The Cronbach's coefficient of this scale was 0.77 .

Knowledge hiding: The knowledge hiding measure was adopted from Peng [11], which contains 3 items. Sample items are "Do not share innovative achievements", and "Do not share helpful information with others". In this study, The Cronbach's coefficient of this scale was 0.82 .

Emotional regulation capability: Emotional regulation capability was measured using 4 items originating from Davies [12]. For example, "I am quite capable of controlling my own emotions.", and "I can always calm down quickly when I am very angry". The Cronbach's a coefficient of this scale was 0.73 .

Control variables: the results of empirical analysis show that gender, age, education, and tenure were related to knowledge hiding [13]. Therefore, we choose these four as control variables in our study.

\section{RESULTS}

\subsection{Confirmatory Factor Analyses}

We first conducted confirmatory factor analyses (CFA) to ensure that our measures had satisfactory discriminant validity. A good model fit requires the values of both CFI and TLI to be greater than 0.90, and the value of RMSEA has to be lower than 0.08 [14]. The CFA results indicated that the hypothesized 4-factor measurement model fit the data well, supporting the discriminant validity for the measured variables. The details of the confirmatory factor analyses can be found in Table 1.
Table1. Results of Confirmatory Factor Analyses

\begin{tabular}{|l|l|l|l|l|l|}
\hline Model & $\mathrm{X}^{2}$ & $\boldsymbol{d f}$ & RMSEA & CFI & TLI \\
\hline $\begin{array}{l}\text { 4-factor } \\
\text { model }\end{array}$ & 120.95 & 84 & .05 & .97 & .96 \\
\hline $\begin{array}{l}\text { one-factor } \\
\text { model }\end{array}$ & 484.97 & 90 & .15 & .62 & .56 \\
\hline
\end{tabular}

Note. $\mathrm{N}=201$.

\subsection{Descriptive Analyses}

Means, standard deviations, and correlation coefficients for all variables in this study are presented in Table 2. As expected, customer aggression was significantly correlated with emotional exhaustion ( $\mathrm{r}=$ $.37, \mathrm{p}<.01)$ and knowledge hiding $(\mathrm{r}=.55, \mathrm{p}<.01)$.

Table2. Means, Standard Deviations, and Correlations of the Focal Variables

\begin{tabular}{|l|l|l|l|l|l|l|l|l|l|}
\hline Variable & Mean & SD & 1 & 2 & 3 & 4 & 5 & 6 & 7 \\
\hline 1.Gender & .57 & .50 & & & & & & & \\
\hline 2.Age & 31.20 & 8.18 & -.12 & & & & & & \\
\hline 3.Education & 2.93 & .57 & .03 & $-.14^{\prime}$ & & & & & \\
\hline 4.Tenure & 8.15 & 7.54 & $-.15^{\circ}$ & $.91^{\prime \prime}$ & $-.20^{* \prime}$ & & & & \\
\hline $\begin{array}{l}\text { 5.Customer } \\
\text { aggression }\end{array}$ & 3.01 & .94 & .07 & .04 & -.12 & .09 & & & \\
\hline $\begin{array}{l}\text { 6.Emotional } \\
\text { regulation } \\
\text { capability }\end{array}$ & 3.73 & .78 & -.09 & $.18^{\prime \prime}$ & .06 & .17 & .13 & & \\
\hline $\begin{array}{l}\text { 7.Emotional } \\
\text { exhaustion }\end{array}$ & 3.49 & .90 & .01 & .02 & .02 & .02 & $.37^{\prime \prime}$ & $.26^{\prime \prime}$ & \\
\hline $\begin{array}{l}\text { 8.Knowledge } \\
\text { hiding }\end{array}$ & 2.77 & 1.11 & -.01 & .07 & -.09 & .04 & $.55^{\prime \prime}$ & .03 & $.31^{\prime \prime}$ \\
\hline
\end{tabular}

Note. $\mathrm{N}=201$. a Dummy variable $(0=$ male, $1=$ female $)$.

$* \mathrm{p}<0.05 ; * * \mathrm{p}<0.01$ (two-tailed).

\subsection{Hypotheses Tests}

We tested our hypotheses using the PROCESS tool, a statistical software package developed by Hayes [15]. The results of these analyses are shown in Tables 3.

As shown in table3, we found that customer aggression has a positive effect on emotional exhaustion $(\beta=.36, p<.01$, see model 1$)$. Therefore, hypothesis 1 was supported.

To test hypothesis 2 , which predicted the mediating role of emotional exhaustion in the relationships between customer aggression and knowledge hiding, we used the PROCESS tool by a bias-corrected bootstrapping procedure (5000 resamples). As shown in table3, customer aggression is positively related to knowledge hiding ( $\beta=.66, p<.01$, see model 3$)$. In addition, when customer aggression and emotional exhaustion were simultaneously entered into model to predict knowledge hiding, emotional exhaustion were significantly related to knowledge hiding $(\beta=.15, p<.05$, see model 4$)$. The bootstrapping analyses (5000 resamples) revealed a significant mediated effect of customer aggression on 
knowledge hiding through emotional exhaustion. The bias-corrected $95 \%$ confidence interval (CI) of the mediated effects did not include zero (95\% CI $[.00, .13])$, indicating support of hypothesis 2 .

In hypothesis 3 , we predicted emotional regulation capability to amplify the positive relationship between customer aggression and emotional exhaustion. In our analyses (Table 3, model 2), the interaction between customer aggression and emotional regulation capability was significantly related to emotional exhaustion $(\beta=$ $.18, \mathrm{p}<.05$, see model 2 ). Therefore, hypothesis 3 was supported.

Table3. Results of Hypothesis Tests

\begin{tabular}{|c|c|c|c|c|}
\hline \multirow[b]{2}{*}{ Variable } & \multicolumn{2}{|c|}{$\begin{array}{l}\text { Emotional } \\
\text { exhaustion }\end{array}$} & \multicolumn{2}{|c|}{ Knowledge hiding } \\
\hline & Model1 & $\begin{array}{c}\text { Model } \\
2\end{array}$ & Model 3 & Model 4 \\
\hline Gender & -.04 & .01 & -.12 & -.12 \\
\hline Age & .01 & .00 & $.05^{\circ}$ & $.04^{\circ}$ \\
\hline Education & .09 & .04 & -.09 & -.11 \\
\hline Tenure & -.01 & .00 & -.05 & -.05 \\
\hline Customer aggression & .36 & .28 & .66 & $.61^{\prime \prime}$ \\
\hline Emotional exhaustion & & & & $.15^{\circ}$ \\
\hline Emotional regulation capability & & 28 & & \\
\hline $\begin{array}{l}\text { Customer aggression } \times \text { Emotional } \\
\text { regulation capability }\end{array}$ & & $18^{*}$ & & \\
\hline$F$ & 6.44 & 2.01 & 18.83 & 16.57 \\
\hline$R^{2}$ & .14 & .07 & .33 & .34 \\
\hline \multicolumn{5}{|c|}{ Bootstrap results for mediated effect } \\
\hline & Effect & $\begin{array}{l}\text { Boot } \\
\text { SE }\end{array}$ & $\begin{array}{c}\mathrm{LL} 95 \% \\
\mathrm{Cl}\end{array}$ & $\begin{array}{l}\text { UL 95\% } \\
\mathrm{Cl}\end{array}$ \\
\hline Emotional exhaustion & .06 & .08 & .00 & .13 \\
\hline
\end{tabular}

Note. $\mathrm{N}=201$. Unstandardized regression coefficients are reported. Bootstrap sample size $=5,000$. LL $=$ lower limit; $\mathrm{CI}=$ confidence interval; $\mathrm{UL}=$ upper limit.

$$
* \mathrm{p}<0.05 ; * * \mathrm{p}<0.01
$$

\section{DISCUSSION AND CONCLUSIONS}

This study shows that customer aggression significantly affects employee knowledge hiding through emotional exhaustion. When employees are bullied and abused by customers, they tend to have negative emotions and increase emotional exhaustion. In other words, customer aggression will promote emotional exhaustion of employees. In addition, this study also found that knowledge hiding was significantly affected by emotional exhaustion and indirectly affected by customer aggression through emotional exhaustion intermediaries. In addition, employees will use their emotional regulation ability to buffer negative emotions caused by customer aggression, but this will increase emotional exhaustion and indirectly promote knowledge hiding.

Theoretically, this finding extends previous research, many of which have demonstrated the effects of customer aggression on employee emotional exhaustion and knowledge hiding. This study points out the importance of knowledge hiding phenomenon in organizational knowledge management from the perspective of emotion.

This research has certain practical significance. Effective detection and knowledge hiding between managers are crucial to the development of modern enterprises. As knowledge concealment is a kind of personal behavior, compared with relatively mature and fixed incentive management, such personal behavior is difficult to be detected by managers but will greatly affect employees' work efficiency. Based on the research in this paper, emotional exhaustion plays a very important role in promoting the phenomenon of knowledge hiding among employees. Managers should take care of employees' emotions in a timely manner, help them adjust or eliminate negative emotions at work, and reduce their emotional exhaustion to avoid the occurrence of knowledge hiding.

To sum up, this study profoundly reveals the influencing factors that lead to the phenomenon of knowledge hiding, and explains the positive influence of customer aggression and emotional exhaustion on knowledge hiding.

\section{REFERENCES}

[1] Park, H., Ribière, V., \& Schulte, W. D. (2004). Critical attributes of organizational culture that promote knowledge management technology implementation success. Journal of Knowledge management, 8(3):106-117.

[2] Bock, G. W., Zmud, R. W., Kim, Y. G., \& Lee, J. N. (2005). Behavioral intention formation in knowledge sharing: Examining the roles of extrinsic motivators, social-psychological forces, and organizational climate. MIS quarterly, 87-111.

[3] Baird, L., \& Henderson, J. C. (2001). The knowledge engine: How to create fast cycles of knowledge-toperformance and performance-to-knowledge. Berrett-Koehler Publishers.

[4] Baranik, L. E., Wang, M., Gong, Y., \& Shi, J. (2017). Customer mistreatment, employee health, and job performance: Cognitive rumination and social sharing as mediating mechanisms. Journal of Management, 43(4), 1261-1282.

[5] Karatepe, O. M., \& Aleshinloye, K. D. (2009). Emotional dissonance and emotional exhaustion among hotel employees in Nigeria. International Journal of Hospitality Management, 28(3), 349-358.

[6] Grandey AA, Dickter DN, Sin HP. The customer is not always right: Customer aggression and emotion regulation of service employees. Journal of Organizational Behavior,2004, 25(3): 397-418.

[7] Baumeister, R. F., Bratslavsky, E., Muraven, M., \& Tice, D. M. (1998). Ego depletion: Is the active self a limited resource?. Journal of personality and social psychology, 74(5), 1252-1265. 
[8] Connelly, C. E., Zweig, D., Webster, J., \& Trougakos, J. P. (2012). Knowledge hiding in organizations. Journal of organizational behavior, 33(1), 64-88.

[9] Shao, R., \& Skarlicki, D. P. (2014). Service employees' reactions to mistreatment by customers: A comparison between North America and East Asia. Personnel Psychology, 67(1), 23-59.

[10] Watkins, M. B., Ren, R., Umphress, E. E., Boswell, W. R., Triana, M. D. C., \& Zardkoohi, A. (2014). Compassion organizing: employees' satisfaction with corporate philanthropic disaster response and reduced job strain. Journal of Occupational \& Organizational Psychology, 88(2), 436-458.

[11] Peng, H. (2012). Counterproductive work behavior among Chinese knowledge workers. International Journal of Selection and Assessment, 20(2), 119138.

[12] Davies, M., Stankov, L., \& Roberts, R. D. (1998). Emotional intelligence: In search of an elusive construct. Journal of personality and social psychology, 75(4), 989-1015.

[13] Smith, E. A. (2001). The role of tacit and explicit knowledge in the workplace. Journal of knowledge Management, 5(4):311-321.

[14] Hu, L. T., \& Bentler, P. M. (1999). Cutoff criteria for fit indexes in covariance structure analysis: Conventional criteria versus new alternatives. Structural equation modeling: a multidisciplinary journal, 6(1), 1-55.

[15] Hayes, A. F. (2013). Introduction to mediation, moderation, and conditional process analysis: A regression-based approach. Guilford publications.

[16] Huo, W., Cai, Z., Luo, J., Men, C., \& Jia, R. (2016). Antecedents and intervention mechanisms: a multilevel study of R\&D team's knowledge hiding behavior. Journal of Knowledge Management, 20(5):880-897.

[17] Baumeister, R. F., Muraven, M., \& Tice, D. M. (2000). Ego depletion: A resource model of volition, self-regulation, and controlled processing. Social cognition, 18(2), 130-150.

[18] Boyd C. Customer violence and employee health and safety. Work, Employment and Society, 2002, 16(1): 151-169.

[19] Brotheridge, C. M., \& Lee, R. T. (2002). Testing a conservation of resources model of the dynamics of emotional labor. Journal of occupational health psychology, 7(1), 57.

[20] Yam, K. C., Fehr, R., Keng-Highberger, F. T., Klotz, A. C., \& Reynolds, S. J. (2016). Out of control: A self-control perspective on the link between surface acting and abusive supervision. Journal of Applied Psychology, 101(2), 292-301. 